This item was submitted to Loughborough's Research Repository by the author.

Items in Figshare are protected by copyright, with all rights reserved, unless otherwise indicated.

\title{
Knowledge displays: soliciting clients to fill knowledge gaps and to reconcile knowledge discrepancies in therapeutic interaction
}

PLEASE CITE THE PUBLISHED VERSION

http://dx.doi.org/10.1016/j.pec.2015.10.006

\section{PUBLISHER}

(C) Elsevier

VERSION

AM (Accepted Manuscript)

\section{PUBLISHER STATEMENT}

This work is made available according to the conditions of the Creative Commons Attribution-NonCommercialNoDerivatives 4.0 International (CC BY-NC-ND 4.0) licence. Full details of this licence are available at: https://creativecommons.org/licenses/by-nc-nd/4.0/

\section{LICENCE}

CC BY-NC-ND 4.0

\section{REPOSITORY RECORD}

Pino, Marco. 2019. "Knowledge Displays: Soliciting Clients to Fill Knowledge Gaps and to Reconcile Knowledge Discrepancies in Therapeutic Interaction”. figshare. https://hdl.handle.net/2134/19621. 
Knowledge displays: soliciting clients to fill knowledge gaps and to reconcile knowledge discrepancies in therapeutic interaction

\author{
Marco Pino ${ }^{1}$
}

\begin{abstract}
Objective: To examine knowledge displays (KDs), a practice by which Therapeutic Community (TC) professionals exhibit previous knowledge about their clients' circumstances and experiences. Methods: Conversation analysis is used to examine 12 staff-led meetings recorded in Italy ( 8 in a drug addiction TC; 4 in a mental health TC).

Results: The TC professionals use KDs within broader sequences of talk where they solicit their clients to share personal information and where the clients provide insufficient or inconsistent responses. In these circumstances, the staff members employ KDs to pursue responses that redress emerging knowledge gaps and discrepancies regarding the clients' experiences or circumstances.

Conclusion: KDs allow the staff members to achieve a balance between respecting their clients' right to report their own experiences and influencing the ways in which they report them. KDs help to reinforce the culture of openness that is central to many forms of therapeutic interaction, to forward the therapeutic agenda and to expand the staff members' knowledge of the clients' experiences and circumstances.

Practice implications: KDs can be used to solicit clients to share personal information. This paper illustrates core features that underlie the function of KDs (where they are used and how they are constructed).
\end{abstract}

Keywords: Addiction, Conversation analysis, Knowledge, Mental health, Therapeutic community

Citation: Pino, M. (2016). Knowledge displays: soliciting clients to fill knowledge gaps and to reconcile knowledge discrepancies in therapeutic interaction. Patient Education and Counseling, 99(6), 897-904. DOI: 10.1016/j.pec.2015.10.006

\footnotetext{
${ }^{1}$ Department of Social Sciences - Loughborough University, UK. t: +44 (0)1509 222544. Email: marco.pino75@gmail.com.
} 


\section{Introduction}

\subsection{Background}

Therapeutic interaction is a form of professional-client communication whose goal is to improve clients' mental health. The expectation that clients share personal information plays a central role in it insofar as the success of therapeutic interactions "depends in some measure on the client's willingness and ability to talk about self and other's experiences" [1, p. 188; also 2]. Sometimes clients fail to disclose personal information, for instance by answering a question with "I don't know" [1,3], by limiting themselves to telegraphic ("yes"/“no") responses, or by providing responses that lack detail [1]. Professionals use several practices to solicit or enable clients to say more about themselves, including silences [1], 'continuers' ("mm hm", "uh huh") [1,4], prompts ("and") [1] and different types of question [1-3,5,6]. These practices promote information exchanges that flow from the client to the professional, shaping and reinforcing an asymmetric relationship in which the client is expected to share personal information and the professional is expected to listen. Although some therapeutic interactions occur on a one-off basis, commonly professionals and clients meet regularly over periods of months and establish ongoing relationships [7]. As they start having a relational history, they increasingly rely on previous knowledge to shape their reciprocal expectations; for instance, clients can be expected to report personal information that is consistent with what they have previously shared (an expectation that applies to social relationships more broadly [8]). However, gaps and discrepancies commonly emerge. Gaps arise when the professional has reasons to believe that the client has personal information that could (or should) be communicated, but the client fails to do so. Discrepancies emerge when the client provides information that contradicts what the professional already knows. In these cases, a tension emerges between taking what the client is saying at face value and soliciting them to provide further information $[9,10]$. This paper examines a communicative practice called knowledge display (KD) by which TC professionals show that they already have some previous knowledge about a client's experience or circumstance and use it to solicit further information that can fill knowledge gaps [11] and reconcile emerging knowledge discrepancies about that experience or circumstance.

\subsection{Therapeutic Community meetings}

The paper focuses on Therapeutic Communities (TCs). The term TC designates both a type of residential or semi-residential service that provides psychosocial rehabilitation for persons with 
diagnoses of mental illness [12-14] or drug addiction problems [15,16] and the therapeutic method employed therein $[17,18]$. The TC method emphasises prolonged interaction between staff and clients (the so-called "living-learning experience" [12] or "community as method" [19,20]), usually over a period of several months [21], in joint work, learning and leisure activities. Staff-led group meetings take place on a weekly basis and are occupied to a significant extent by clients' reports of their recent activities and experiences [22,23]. Sharing personal information is valued for its therapeutic implications; for instance, by reporting the difficulties they encounter, TC clients can engage in self-reflection and receive feedback and support from others [24]. However, clients can fail to share personal information for several reasons. For instance, they may be reluctant to expose their vulnerability, particularly in a group setting, or they may want to conceal some information. TC programs have a social control component whereby staff members monitor clients' behaviours for their adherence to institutional rules (e.g. abstinence from drug use) [16]. When they withhold information about their recent activities, clients may be resisting this agenda. Whatever TC clients' motives for withholding information may be, TC professionals have an interest in soliciting clients to share, partly to promote the therapeutic agenda of the meetings and partly to ascertain clients' adherence to institutional rules [10]. Through the practice examined in this paper (KD) TC staff members invoke some previous knowledge about their clients as a resource for soliciting them to expand their personal reports and, in turn, to further increase the staff members' knowledge of the clients' experiences and circumstances.

\subsection{Displays of knowledge as "fishing" practices}

The findings presented in this study are linked to two strands of research in conversation analysis. The first one stems from seminal research by Pomerantz [25] on how speakers "pursue a response" in circumstances where an interlocutor has failed to provide it. Muntigl and Zabala [1] explored this phenomenon in therapeutic interactions by analysing the ways in which therapists treat their clients' responses as insufficient ("expandable") and employ communicative practices to solicit the clients to expand.

The second line of research goes back to another seminal study, in which Pomerantz [26] described the practice of "telling my side". This is an assertion (e.g. "Your line's been busy"), which communicates partial knowledge of an interlocutor's circumstance and works as a "fishing device", soliciting the interlocutor to provide more information (in the example above, why their line was busy). Bergman [10] showed how "fishing" is employed in psychiatric intake interviews 
and Peräkylä and Silverman [5] explored a related phenomenon in AIDS counselling sessions [also 27].

The study reported here explores the intersection of these two phenomena in TC meetings: instances where professionals treat their clients' responses as insufficient and in need of expansion by displaying previous knowledge of circumstances/experiences that the clients could (and should) report.

\section{Methods}

\subsection{Conversation analysis}

This study employs conversation analysis (CA), a method for the study of how participants accomplish social actions through the use of spoken language and bodily conduct [28-30]. This method has been extensively employed to study communication between healthcare professionals and patients. CA relies on recorded episodes of naturally occurring social interaction, examined alongside detailed transcripts which represent not only what was said, but how it was said (e.g. in terms of speech delivery, intonation, timing, etc.) [31].

\subsection{Data}

Data for this study consist of 4 meetings audio-recorded in a TC for people with mental health diagnoses (mostly of schizophrenia) and 8 meetings (4 audio and 4 video) recorded in a TC for people with drug addiction problems (mostly related to heroin use) (both TCs are in Italy). The Mental Health TC meetings were regularly attended by two TC professionals (an educator and a nurse) and a number of clients that varied between 7 and 12. The Addiction TC meetings were attended by 2 educators and a number of clients that varied between 3 and 5. The TC professionals are referred to as staff members throughout the paper. All participants provided informed consent and authorised publication of anonymised transcripts.

The recordings were examined alongside the transcripts to identify instances where the TC professionals use KDs. KDs were defined as conversational turns where the TC professionals exhibit some previous knowledge of the clients' circumstances or experiences (as we shall see, the turns that contain KDs can also contain additional components that perform some accompanying action); "previous" refers to knowledge that the staff describe as having been gained some time prior to the meeting. The search identified 18 instances of KDs (10 in the Addiction TC data and 8 
in the Mental Health TC data). The TC professionals use these KDs within the broader activity of soliciting the clients to share personal information. This paper does not deal with how the TC professionals display knowledge about the clients within other types of activity (e.g. assessing, advising, etc.). The transcripts in this paper contain a double line: original Italian and idiomatic English translation. A list of transcription conventions is provided in Appendix A.

\section{Results}

3.1 KDs solicit clients to share personal information

KDs are a communicative practice (i.e. a way of accomplishing a social action [32]) through which the staff members implement the action of soliciting the clients to share personal information. The staff employ KDs in the third position of a sequence of talk composed of 4 parts (highlighted in the extracts): (1) a staff member solicits a client to share personal information; (2) the client responds; (3) a staff member produces a KD, which treats the client's response as insufficient and in need of expansion [1]; (4) the client responds to the KD. KDs treat the clients' responses as insufficient either because they are incomplete (Table 1) or because they contradict what the staff already know (Table 2).

Table 1

Extract 1 (Addiction TC; INT8:47,59)

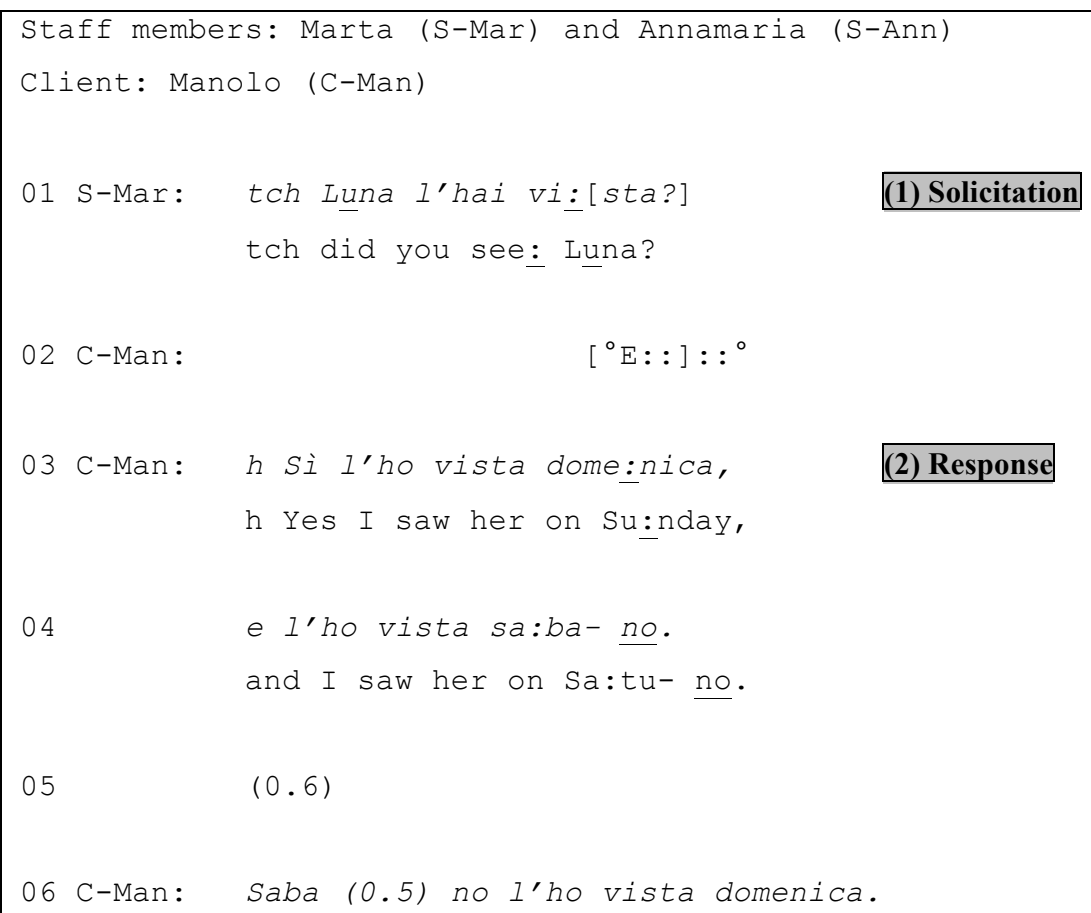




\begin{tabular}{|c|c|}
\hline & Satu (0.5) no I saw her on Sunday. \\
\hline 07 & $(1.0)$ \\
\hline 08 C-Man: & $\begin{array}{l}>\text { Sa }[\text { bato }-<(.) \text { no sabato }= \\
>\text { Saturday }-<(.) \text { no Saturday }=\end{array}$ \\
\hline 09 S-Mar: & $\begin{array}{c}\text { Mh } \\
\mathrm{Mh}\end{array}$ \\
\hline 10 C-Man: & $\begin{array}{l}=\text { non } I^{\prime} \text { ho vista. } \\
=\text { I didn't see her. }\end{array}$ \\
\hline 11 S-Ann: & $\begin{array}{l}\text { Scrivevi nella programmazione } \\
\text { You wrote in your planning }\end{array}$ \\
\hline 12 & $\begin{array}{l}\text { che forse sareste usciti, } \\
\text { that maybe you would go out, }\end{array}$ \\
\hline 13 & $\begin{array}{l}\text { e non sapevi bene cosa avreste fatto? } \\
\text { and you didn't know exactly what you would be doing? }\end{array}$ \\
\hline 14 & $(0.3)$ \\
\hline 15 S-Ann: & $\begin{array}{l}\text { Cosa avete fatto. } \\
\text { What did you do. }\end{array}$ \\
\hline 16 C-Man: & $\begin{array}{l}\text { Siamo andati al centro commercia }{ }^{2} \text { le, (1.1) (4) Response } \\
\text { We went to the shopping ce: :ntre, (1.1) }\end{array}$ \\
\hline 17 & 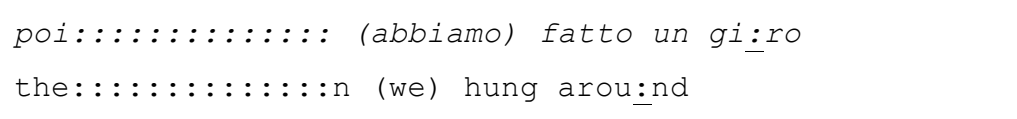 \\
\hline 18 & $\begin{array}{l}\text { e siamo stati acca:sa, (0.7) poi basta. } \\
\text { and we stayed at ho:me, (0.7) and that's it. }\end{array}$ \\
\hline
\end{tabular}

Before extract 1 (Table 1 - Addiction TC) a staff member has asked a client (Manolo) to report on his activities during the weekend outside the TC (data not shown). A staff member (Marta) asks Manolo whether he saw someone called Luna (line 1). Although it is produced as a yes-no question [33], Marta's question solicits an expanded report [1,34,35]. Manolo fails to provide it and instead displays trouble in recalling when he saw Luna (lines 3-10). Another staff member (Annamaria) produces a KD invoking previous knowledge about Manolo's plans for the weekend (lines 11-13): "You wrote in your planning that maybe you would go out, and you didn't know exactly what you 
would be doing?" (Annamaria refers to a written plan that the clients are required to complete each Friday in preparation for the weekend). By mentioning this information, Annamaria treats Manolo's response as incomplete and presents a direction that Manolo can take to expand his personal report (by detailing what he did with Luna). After an 0.3 seconds silence (line 14), Annamaria pursues a response by explicitly asking Manolo to report what he did with Luna (which he does at lines 16$18)$.

\section{Table 2}

Extract 2 (Mental Health TC; Rg2C:30)

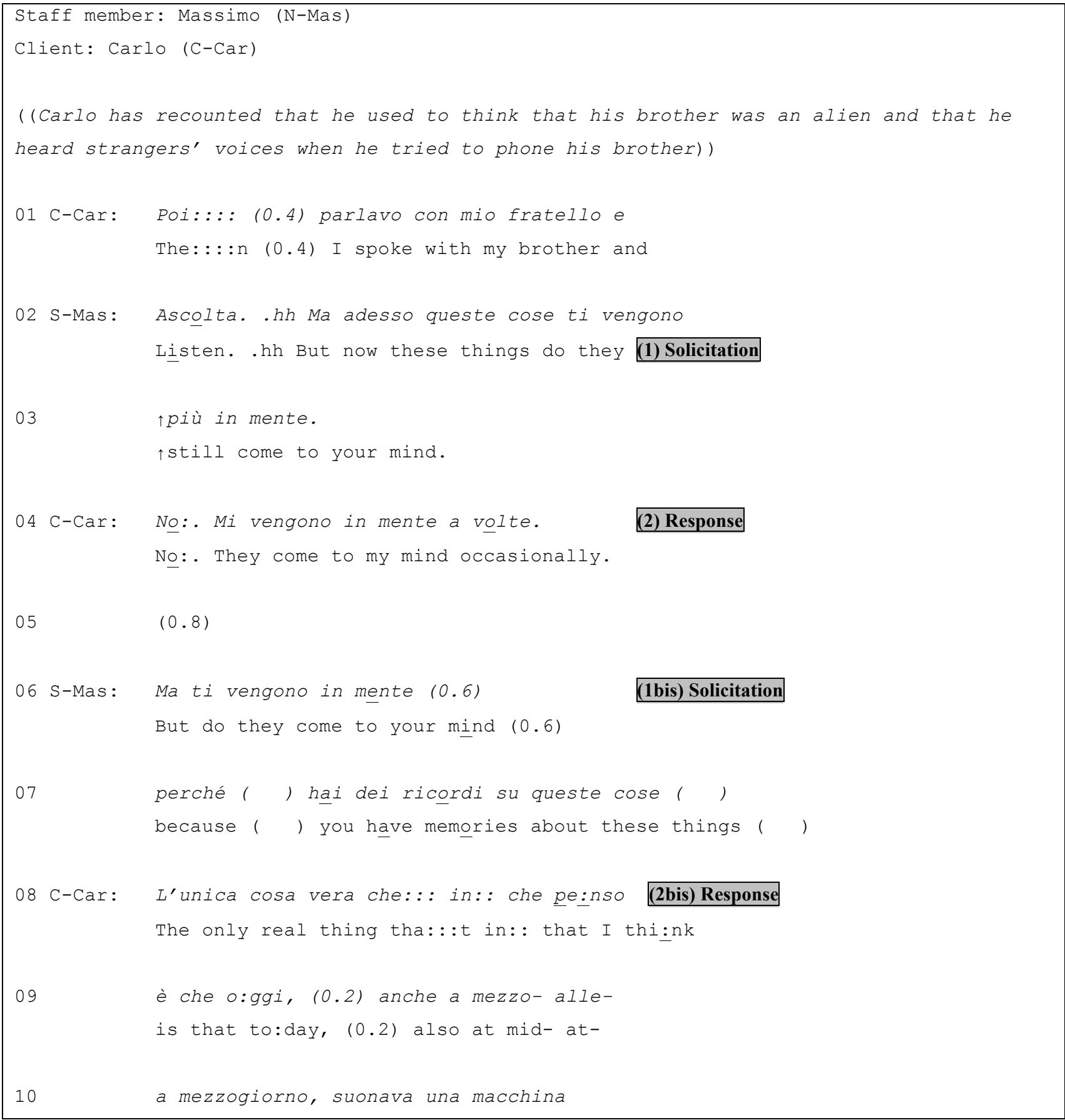




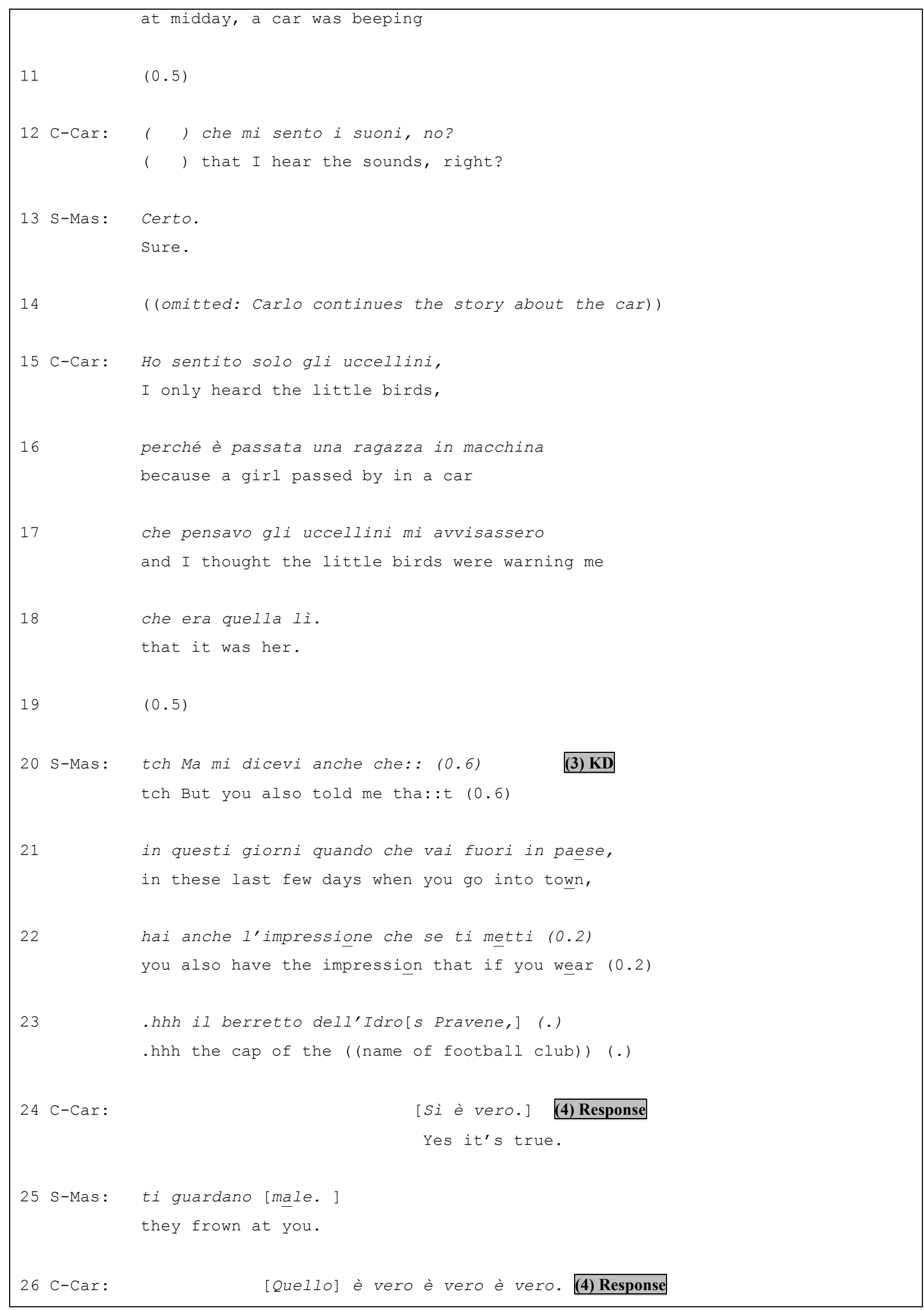




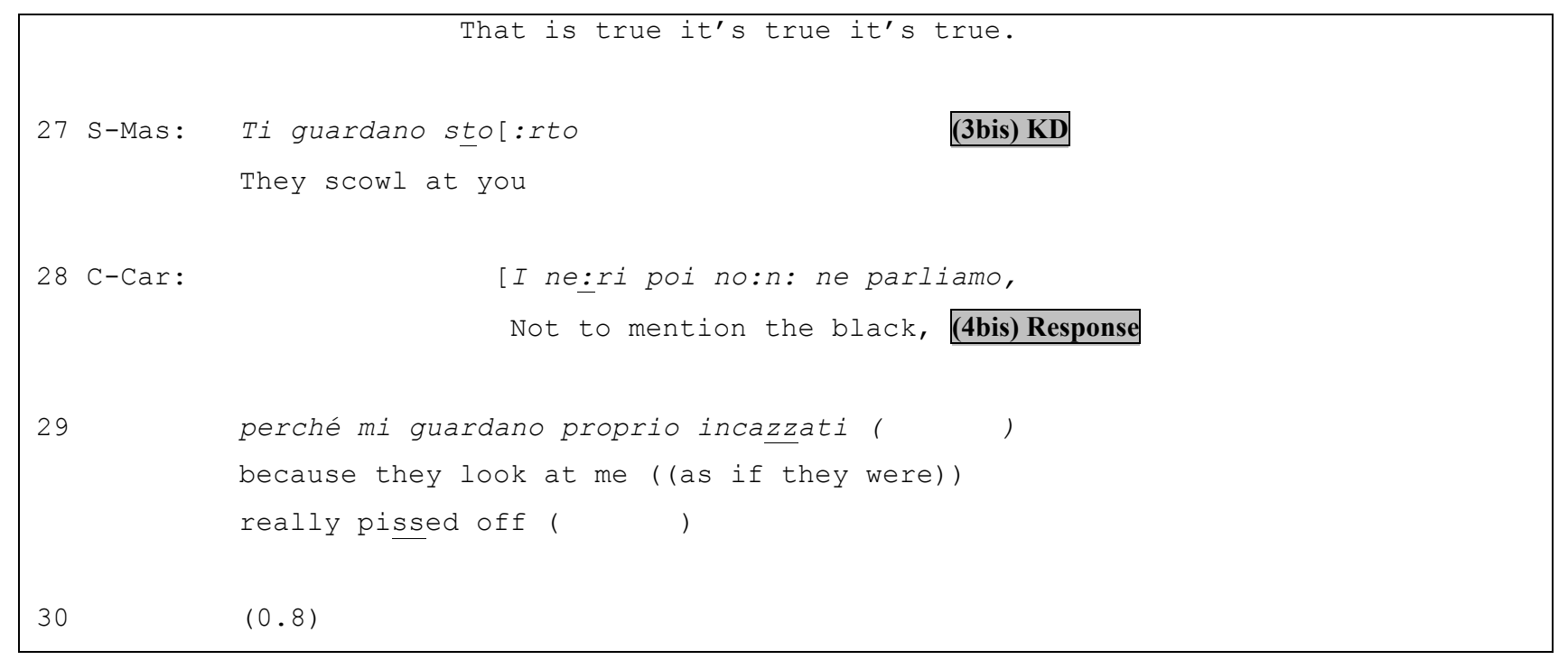

Before extract 2 (Table 2 - Mental Health TC), a client (Carlo) has described some events (possibly hallucinations) that he experienced in the past (the final part of his story is reproduced in line 1). A staff member (Massimo) starts a line of questioning (lines 2-3) to establish whether Carlo is still experiencing such events (hallucinations) or whether he is reminiscing about things that he experienced in the past (Massimo pursues this matter again at lines 6-7, after Carlo's response at line 4). Carlo recounts a story involving a car beeping at him, a mysterious girl and little birds communicating with him (lines 8-18). He claims that this is the only experience that he believes was "real" (with the implication that other people may regard this experience as unreal, e.g. as a hallucination, whereas he does not). There is also an implicit claim that for Carlo there are no other such experiences to report (it is "the only" episode that he considers as "real", line 8). Massimo produces a KD, which treats Carlo's response as discrepant with some previous knowledge (lines 20-23, 25 and 27): Carlo previously reported another experience (this experience, which involves people on the street frowning at Carlo, has in common with the previous one that other people may regard it as 'unreal' or at least exaggerated, whereas Carlo does not). The KD thus lays out a direction that Carlo can take to expand his report and to reconcile the emerged discrepancy (which Carlo does at lines 28-29).

To summarise, KDs treat the clients' responses to the staff members' initial inquiries as insufficient or discrepant with some previous information; KDs provide for the clients to redress these gaps and discrepancies by laying out a direction for the expansion of the clients' reports. The next section examines in more detail the type of response that KDs solicit.

3.2. KDs solicit [confirmation + expansion] responses 
KDs provide for the clients to confirm the information conveyed through the $\mathrm{KD}$ and to expand their personal reports along the lines indicated in the KD. That this is the relevant course of action following a KD is evidenced, first of all, in the fact that the clients recurrently respond to the staff members' KDs by confirming the information conveyed in it and by expanding their reports. In 4/18 cases, the clients confirm and expand after the KD (see Table 3); in 6/18 additional cases, the clients do not initially produce an expansion in response to a KD (e.g. they only confirm the information), however the staff pursue an expansion, which the clients then produce (see Tables 1 and 2). Through their [confirmation + expansion] responses, the clients treat the staff members' KDs as doing two things [35]: claiming something about the clients' circumstances or experiences (i.e. something that the clients did or felt), and soliciting a more expanded report of those experiences/circumstances.

Table 3

Extract 3 (Mental Health TC; Rg3A1:128)

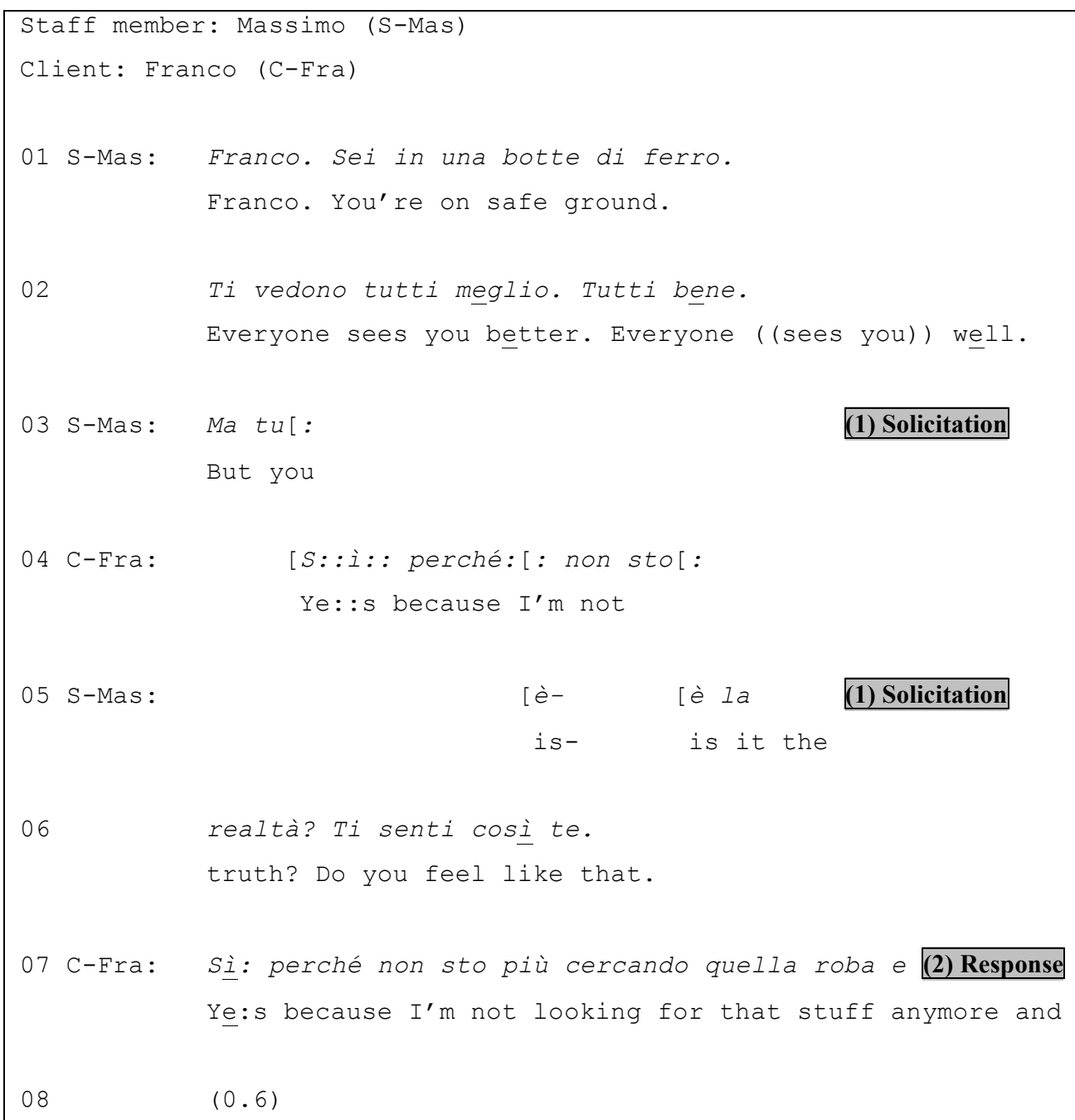




\begin{tabular}{|c|c|}
\hline 09 S-Mas: & $\begin{array}{l}\underline{A}: h \\
\underline{A}: h\end{array}$ \\
\hline 10 & $(2.6)$ \\
\hline 11 S-Mas: & $\begin{array}{l}\text { Quindi tü non cerchi più quella roba. } \\
\text { So you're not looking for that stuff anymore. }\end{array}$ \\
\hline 12 & $\begin{array}{l}\text { Non ne senti più il bisogno. } \\
\text { You don't feel the need for it anymore. }\end{array}$ \\
\hline 13 & $(1.1)$ \\
\hline 14 C-Fra: & $\begin{array}{l}{ }^{\circ} \text { No eh. }{ }^{\circ} \\
{ }^{\circ} \text { No eh. }{ }^{\circ}\end{array}$ \\
\hline 15 & $(3.9)$ \\
\hline 16 S-Mas: & $\begin{array}{l}. h h \text { No perché nói siamo an- }(0.2) \\
\text { hh No because we are al- (0.2) }\end{array}$ \\
\hline 17 & $\begin{array}{l}\text { a dir la verità un pochino preoccupati, } \\
\text { to be honest a little bit worried, }\end{array}$ \\
\hline 18 & $\begin{array}{l}\text { perché: }(0.8) \text { ti vediamo: : un (1.1) } \\
\text { because }(0.8) \text { we see you a }(1.1)\end{array}$ \\
\hline 19 & $\begin{array}{l}\text {.hh un po' asse } \underline{n} \text { te. Un po' isolato. Un po' distacca:to. } \\
\text {.hhh a bit abse:nt. A bit isolated. A bit deta:ched. }\end{array}$ \\
\hline 20 & 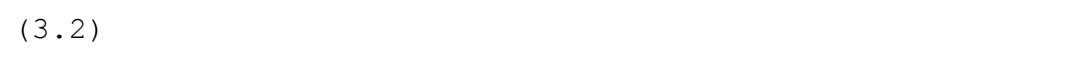 \\
\hline 21 C-Fra: & $\begin{array}{l}{ }^{\circ} \mathrm{Si} \text { perché certe volte } \\
{ }^{\circ} \text { Yes because sometimes }\end{array}$ \\
\hline 22 & $\begin{array}{l}\text { sto un po' ma:le:: : (e allora) } \\
\text { I feel a bit ba: : : : d (and so) }\end{array}$ \\
\hline 23 & $(4.9)$ \\
\hline
\end{tabular}

In extract 3 (Table 3 - Mental health TC), the client responds to the KD with a [confirmation + expansion]. Other clients attending the meeting said that they saw an improvement in Franco's (a client) behaviour (data not shown). Staff member Massimo summarises these clients' views (lines 1-2) and asks Franco about his own view on this matter (lines 3, 5-6) [5]. Franco confirms that he is 
doing better because he is not looking for "that stuff" (i.e. illegal drugs) anymore. Massimo produces a tepid uptake (“Ah", line 9), followed by a 2.6 seconds silence and a summary of Franco's answer (lines 11-12) [36], followed by a 1.1 seconds silence; these moves give Franco opportunities to expand his response [1] but he only gives a confirmation ("No eh", line 14). Massimo then produces a KD (lines 18-19), which treats Franco's response as contradicting previous knowledge that the client is not doing well (the KD is preceded by "No because we are alto be honest a bit worried", which conveys another reason for pursuing additional information: the staff are worried about his wellbeing). Franco does not respond immediately: a 3.2 seconds silence develops (line 20) (this is not uncommon in the interactions between Franco and the staff, who recurrently allow significant silences after questions addressed to him); Franco subsequently confirms this information ("Yes") and expands by reporting that sometimes he feels a bit bad (lines 21-22).

In Tables 1 and 2 the clients do not initially expand their reports in response to a KD and the staff pursue an expansion [25]. This provides evidence that the staff treat a [confirmation + expansion] as an appropriate response following a KD. In extract 2 (Table 2), Carlo only confirms the information conveyed through the KD but he does not expand his report (lines 24 and 26). Massimo then re-completes the KD (line 27) by reformulating its final component (previously produced at line 25), thereby signalling to Carlo that his response to the KD is insufficient. Carlo then expands his personal report (lines 28-29). In Extract 1 (Table 1), an 0.3 seconds silence emerges after the staff member's KD (line 14); the staff member then overtly pursues an expansion of the client's personal report ("What did you do"), which the client provides (lines 16-18). This shows that the staff members can treat an emerging silence as missing response on the client's part [25] (Table 3 illustrates a different way of managing a post-KD emerging silence: the staff member allows a 3.2 gap to develop at line 20 and the client eventually produces an expansion). Extract 1 (Table 1) differs from the other cases in that the client expands without confirming the information carried in the KD; this is because the staff member's question ("What did you do") directly pursues an expansion although the client has not yet confirmed the information conveyed in the KD. For some reason, the staff member seems to assume that this information (that the Manolo went out with Luna in the weekend) is correct and does not require confirmation.

There is additional evidence that the clients treat the staff members' KDs as soliciting [confirmation + expansion] responses. In some of the 8/18 cases where the clients do not respond with a [confirmation + expansion], they nevertheless display an understanding that KDs solicit this type of response. 


\section{Table 4}

Extract 4 (Addiction TC; IntV2:1361)

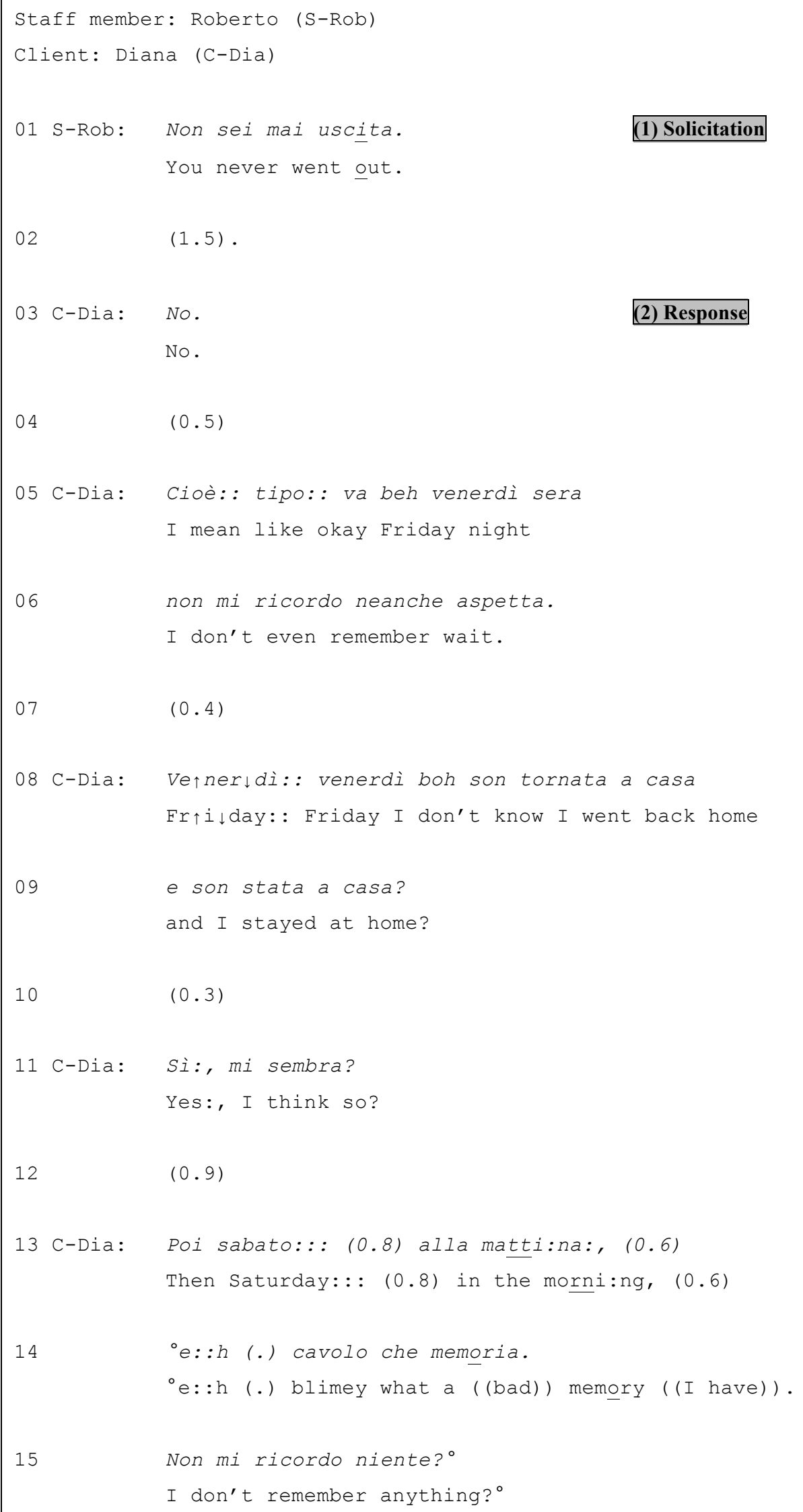




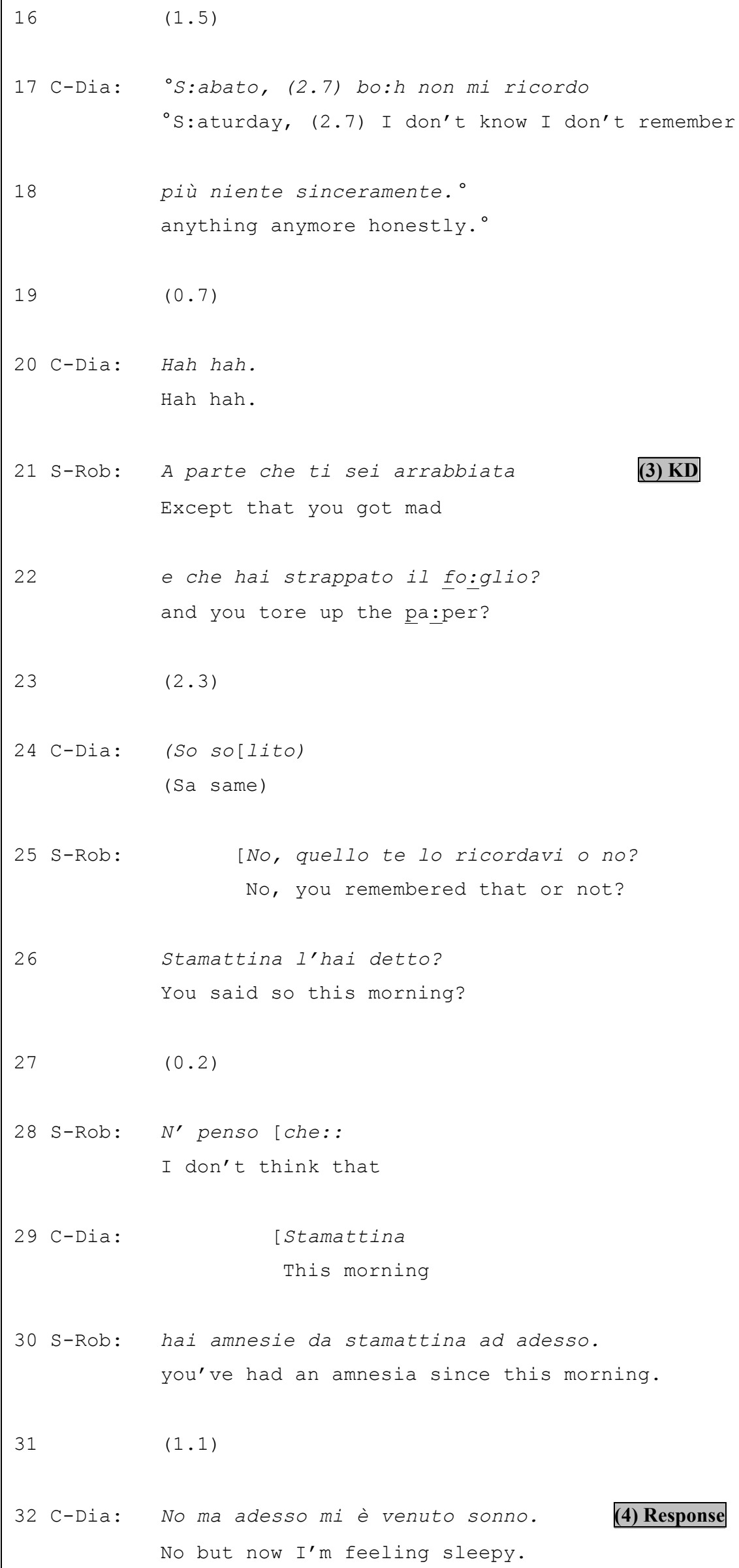


In Extract 4 (Table 4) an educator (Roberto) solicits a client (Diana) to report whether she went out in the weekend (line 1). After a negative answer (line 3), Diana both displays difficulty in recalling what she did and overtly states that she does not remember (lines 6, 14, 17-18) [37]. Roberto produces a KD, which treats Diana's response as contradicting previous knowledge (lines 21-22) that she got "mad" (the KD is prefaced with the words "except that", which set a contrast between this information and the client's claim that she does not remember and, hence, that there is nothing that she can report). After a 2.3 seconds silence and overlapping Diana's hard-to-hear response at line 24 (in which she might be downplaying the significance of the episode by saying that it is the "same" kind of thing that tends to happen to her), Roberto overtly challenges the idea that Diana does not remember (lines 25-30). The staff member thereby pursues a [confirmation + expansion], which the client has not produced in response to the KD. Diana confirms that she has not forgotten ("No", line 32) but, instead of expanding her report, she invokes an alternative reason for her inability to report (sleepiness). By giving a reason for not expanding, Diana displays an understanding that the KD solicits an expansion of her report on the weekend.

\section{Table 5}

Extract 5 (Mental Health TC; Rg1A:437)

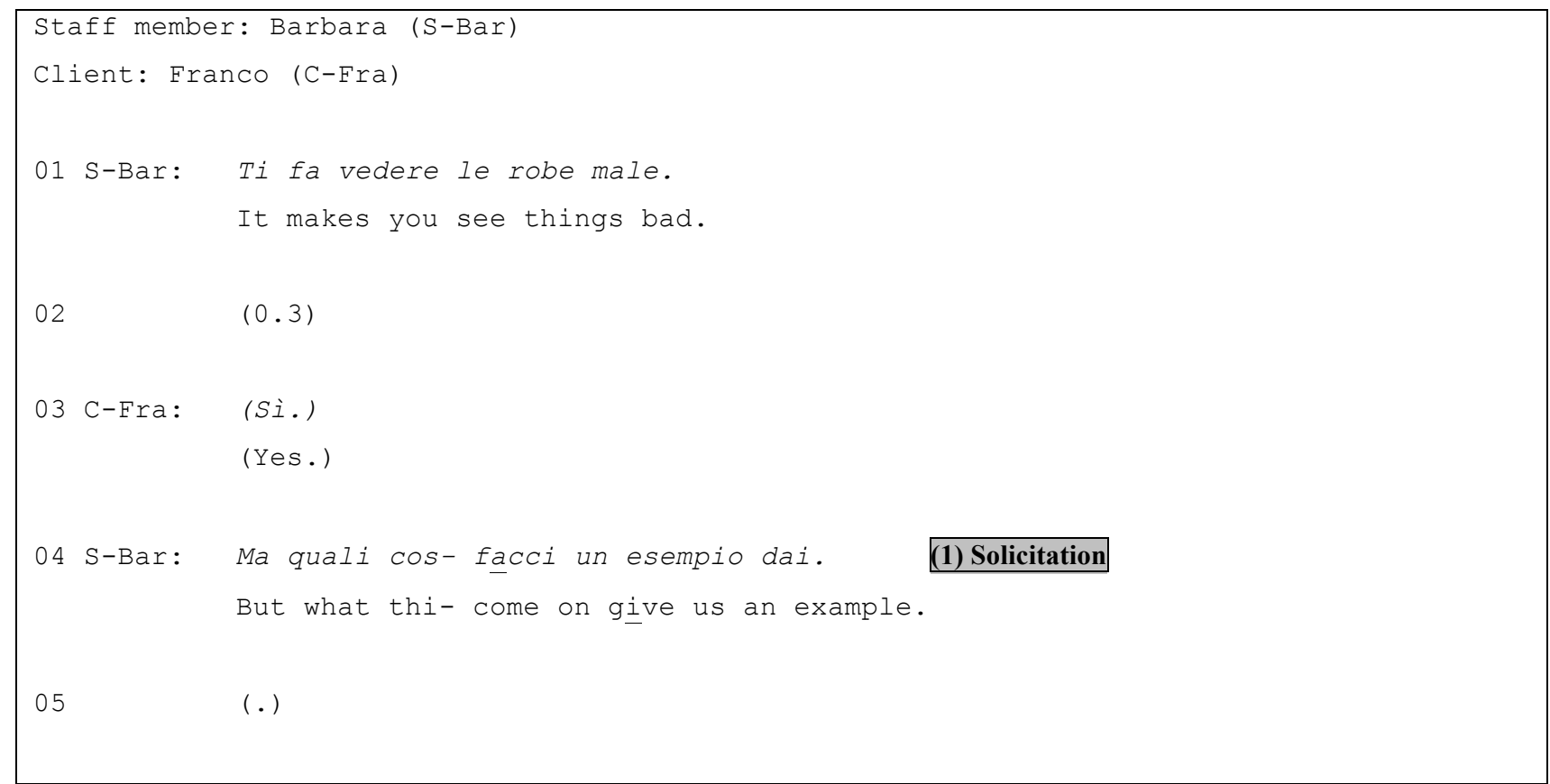


Pino - Knowledge displays in therapeutic interaction

\begin{tabular}{|c|c|c|}
\hline 06 & S-Bar: & $\begin{array}{l}\text { Perché faccio [un po' fati]ca- } \\
\text { Because I'm struggling a bit- }\end{array}$ \\
\hline 07 & C-Fra: & $\begin{array}{l}\text { [ Tutte le cose.] } \\
\text { All things. }\end{array}$ \\
\hline 08 & & $(0.6)$ \\
\hline 09 & S-Bar: & $E: h ?$ \\
\hline & & $E: h ?$ \\
\hline 10 & & $(0.5)$ \\
\hline 11 & C-Fra: & $\begin{array}{l}\text { Tutte le cose. } \\
\text { All things. }\end{array}$ \\
\hline 12 & & $(4.7)$ \\
\hline 13 & S-Bar: & $\begin{array}{l}\text { Ma e::: }: \text { (0.3) quando eri:::::: a (city)) però (0.6) (3) KD } \\
\text { But e::::h (0.3) when you were in ( (city)) though (0.6) }\end{array}$ \\
\hline 14 & & $\begin{array}{l}\text { non l'hai presa giulsto. } \\
\text { you didn't take it did you. }\end{array}$ \\
\hline 15 & C-Fra: & $\begin{array}{l}\text { [Si che I'ho presa. (4) Response } \\
\text { Yes I took it. }\end{array}$ \\
\hline 16 & & (.) \\
\hline 17 & S-Bar: & $\begin{array}{l}\text { Eh. } \\
\text { Eh. }\end{array}$ \\
\hline 18 & & $(1.0)$ \\
\hline 19 & S-Bar: & $\begin{array}{l}\text { Hai detto tu che non l'hai [presa sempre. } \\
\text { You said that you didn't take it all the time. }\end{array}$ \\
\hline 20 & C-Fra: & $\begin{array}{l}\text { [No I'ho presa. } \\
\text { No I took it. }\end{array}$ \\
\hline
\end{tabular}

Extract 5 (Table 5 - Mental Health TC) illustrates another way in which the clients can avoid expanding their reports: disconfirming the information contained in the KD. This further demonstrates that the clients treat the staff members' KDs as making a claim about their experiences or circumstances. By disconfirming this claim, the clients can avoid expanding their 
personal report along the lines indicated in the KD. Before extract 5 (Table 5) Franco said that he does not want to take psychotropic medication anymore because it makes him "see things bad" (data not shown), a response that Barbara (staff member) summarises at line 1. Barbara then solicits Franco to provide more details (lines 4-6) but Franco gives generic responses, which fail to detail the nature of his symptoms (lines 7, 11). Barbara then produces a KD (lines 13-14), which treats Franco's report (specifically the idea that his medication is causing problems with his vision) as contradicting previous knowledge that Franco stopped taking the medication during his stay in another city (with the implication that this could be the cause of his symptoms rather than side effects of the medication [38]). The KD solicits an expansion of Franco's report to reconcile this emerging discrepancy. However, Franco disconfirms the information conveyed through the KD (line 15); by so doing, he also resists expanding his report along the lines indicated in the KD. By insisting that he took the medication (line 20) Franco conveys that, from his standpoint, Barbara's information is incorrect, that there is no discrepancy to reconcile and hence that an expansion of his report is not required. The staff member pursues a confirmation (line 19) but the client disconfirms again the information contained in the KD (line 20).

\subsection{Where KDs are used and how they are constructed}

Two aspects are important to understand how KDs work: where they are used and how they are constructed. In terms of where, KDs are used in the third position of a larger sequence. In the first position, the staff members solicit the clients to report personal information. In the second position, the clients provide a response, which the staff members treat as insufficient. In the third position, the staff members employ a KD [25] to forward the agenda of the question produced in the first position (soliciting a personal report), to address an emerging problem with the completeness of the client's response, or its consistency with some previous knowledge, and to pursue a response that redresses that problem.

In terms of how they are constructed, KDs accomplish a shift from an unknowing to a knowing position [39]. For instance, in extract 3 (Table 3), line 6, the staff member's question is done from an unknowing position [26]: it targets personal experiences, which are by definition know to the client [40], and it does not suggest that the staff member may already have some knowledge about them. The KD at lines 18-19 accomplishes a shift to a knowing position: the staff member now displays that he already has some knowledge about the client's experience [26]. Transitioning from an unknowing to a knowing position enables the staff to challenge [41] the clients' implicit (Table 2, line 8) or explicit (Table 4, lines 17-18) claims that they have nothing to 
report or that there is some impediment preventing them from reporting (Tables 1 and 5); KDs convey pre-existing knowledge that there are circumstances/experiences that the clients can and should report. This challenging function is recurrently signalled by the initial components in the turns containing KDs, which forecast some form of disagreement (Table 2, line 20, "But you also told me that"; Table 3, line 16, "No because we are [...] a bit worried"; Table 4, line 21, "Except that you got mad"; Table 5, line 13, "But when you were in ((city))"). Additionally, the staff support their KDs, and the challenges that they convey, with two types of evidence [42]. First, the staff refer to information that the clients have already shared on a prior occasion either verbally (Table 4, line 26, "You said so this morning") [43] or in writing (Table 1, line 11, "You wrote in your planning"). This type of KD appears designed to make it harder for the clients to withhold information insofar as, if the clients persist in their claim that they have nothing else to report, they risk contradicting information that they have previously shared [44]. Second, the staff ground some KDs on their own 'reading' of the clients' behaviour [45]. In extract 3 (Table 3), the client reports that his condition has improved; the staff member's KD challenges this on the basis that the client's behaviour suggests otherwise ("We see you a bit absent"). This type of KD can be hard for the clients to dismiss for two reasons. First, it is based on information that the clients 'give away' through their observable behaviour, which is by definition hard to control [45]. Second, because 'reading' the clients' behaviour is within the remit of the staff members in their capacity as support workers, their observations regarding these matters can be hard to dismiss. Finally, in some cases the staff members do not provide the source of the KD and treat their knowledge as certain, with no need to declare its origin (Table 4, lines 21-22; Table 5, lines 13-14). However, when the clients fail to expand their reports following a KD, the staff members pursue an expansion by showing the source of that knowledge [8], thus treating it as something that the clients cannot easily dismiss and exerting increasing pressure on the clients to produce a [confirmation + expansion] response (e.g. Table 4, line 26, "You said so this morning" and Table 5, line 19, "You said that you didn't take it all the time").

\section{Discussion and conclusion}

\subsection{Discussion}

A central task in therapeutic interactions is to manage the boundary between respecting clients' primary right to voice their own experiences [5] and influencing the ways in which they report those experiences [46]. In the TC meetings examined in this study this tension emerges when the clients 
fail to share personal information or do so in ways that contradict some previous knowledge. The TC staff members address this problem by momentarily shifting the distribution of prerogatives that characterizes the therapeutic relationship: through the use of KDs, they step out of their role as recipients of the clients' reports and disclose some personal information on the clients' behalf. The staff members subsequently reposition themselves as recipients and pass the baton on to the clients again with the conveyed expectation that they expand their personal report along the lines indicated in the KD. Through the use of KDs the staff members achieve a balance between influencing how the clients report their own experiences and preserving the clients as the primary authors of their own personal reports [5].

The use of KDs contributes to reinforcing a culture of sharing $[12,47]$ in which the clients are expected to be open about themselves [22]. By soliciting the clients to share personal information, the staff forward the therapeutic agenda of the meetings (e.g. fostering self-reflection and mutual support and feedback) and maintain a regime of scrutiny in which the clients' conduct is monitored for its adherence to institutional rules and expectations [38]. For instance, in the Addiction TC, it is important for the staff that the clients report on their activities outside the physical space of the TC (particularly in the weekend, when the TC is closed; extracts 1 and 4); this enables them to monitor, amongst other things, whether the clients abide by the rules of the rehabilitation programme, which forbid drug use and engagement in illegal and antisocial conduct.

A question worth addressing is: if the staff members already have information about the clients' experiences or circumstances why do they not use it straight away? One possibility is that, by starting with first position solicitations that adopt an unknowing position, the staff members defer to the clients' knowledge about their own experience. This is in line with the orientation in support groups [24] (and perhaps in social interaction more generally [48]) to defer to people's right to voice their own experience (as opposed to the alternative of voicing it on their behalf; for other examples of professionals treating their clients' as knowledgeable agents see [49/this issue,50/this issue]). It is only after the clients have failed to share information (or have reported information that contradicts some previous knowledge) that the staff members temporarily override the clients' primary right to report their own experiences. KDs accomplish a small incursion into the clients' experiential domains (domains of knowledge over which the clients have primary authority [39,40,51-55]) to indicate that there is something that the clients can (and are expected to) report. Once the staff members have done this small incursion, the ball is back in the clients' court and the clients are expected to expand their personal report along the lines laid out in the KD.

\subsection{Conclusion}


This study documented how TC staff members employ KDs, i.e. the practice of displaying previous knowledge about TC clients' experiences and circumstances, to solicit them to expand their personal reports. Through the use of KDs, the staff members capitalize on the knowledge gained during their ongoing relationship with the clients and use it as a resource to solicit more personal information, which in turn contributes to expanding the staff members' knowledge base of the clients' experiences and circumstances.

\subsection{Practice implications}

TC staff members use KDs to solicit their clients to expand their personal reports; they use them after the clients have provided incomplete or inconsistent responses to an initial solicitation to report personal information. KDs appear specifically designed to make it harder for the clients to withhold information because they convey that the staff already have some knowledge about things that the clients could (and should) report. The outcome (i.e. whether clients expand their reports of not) is contingent upon negotiations that occur on a case-by-case basis: clients can confirm the information conveyed through the $\mathrm{KD}$ and expand their reports; they can initially withhold expanding their reports and expand them only after the staff members further pursue an expansion; or they can resist expanding their reports altogether.

Although this study documented the use of KDs in TC meetings, their relevance arguably extends to therapeutic settings where (a) it is important for the professionals to elicit exhaustive and consistent personal reports from the clients, and where (b) the professionals establish an ongoing relationship with the clients (and hence accumulate a significant amount of information about them). Future research is needed to establish whether and how KDs are employed in other therapeutic settings.

I confirm all personal identifiers have been removed or disguised so the persons described are not identifiable and cannot be identified through the details of the story.

\section{Appendix A. Transcription conventions}

The transcription style used in this paper was devised by Gail Jefferson [31] and is commonly used in CA to capture several aspects of speech production including temporal relationships (silences, overlaps) and intonation. The symbols employed in this paper are illustrated in what follows. 


\begin{tabular}{|c|c|}
\hline $\begin{array}{l}\text { S-Mar } \\
\text { C-Man }\end{array}$ & $\begin{array}{l}\text { Participant role ( } \mathrm{S} \text { for staff, } \mathrm{C} \text { for client) followed by the first three letters of } \\
\text { their pseudonym }\end{array}$ \\
\hline , ? & $\begin{array}{l}\text { Punctuation captures intonation, not grammar: Comma is for slightly upward } \\
\text { 'continuing' intonation; question mark for marked upward intonation; and } \\
\text { period for falling intonation. }\end{array}$ \\
\hline[ & Left-side brackets indicate where overlapping talk begins. \\
\hline ] & Right-side brackets indicate where overlapping talk ends. \\
\hline $\begin{array}{l}(0.8) \\
(.)\end{array}$ & $\begin{array}{l}\text { Numbers in parentheses indicate silences in tenths of a second. A period inside } \\
\text { parentheses is a silence less than two-tenths of a second. }\end{array}$ \\
\hline wo:::rd & $\begin{array}{l}\text { Colons indicate a lengthening of the sound just preceding them, proportional } \\
\text { to the number of colons. }\end{array}$ \\
\hline WO- & $\begin{array}{l}\text { A hyphen indicates an abrupt cut-off or self-interruption of the sound in } \\
\text { progress indicated by the preceding letter(s). }\end{array}$ \\
\hline word & $\begin{array}{l}\text { Underlining indicates stress or emphasis (usually conveyed through slightly } \\
\text { rising intonation). }\end{array}$ \\
\hline$\uparrow \downarrow$ & An arrow symbol indicates a marked pitch rise or fall. \\
\hline$=$ & $\begin{array}{l}\text { Equal signs at the end of one line and the start of an ensuing one indicate a } \\
\text { "latched"' relationship - no silence at all between them. }\end{array}$ \\
\hline$(\quad)$ & $\begin{array}{l}\text { Empty parentheses indicate talk too obscure to transcribe. Words inside such } \\
\text { parentheses indicate a best estimate of what is being said. }\end{array}$ \\
\hline hhh .hhh & $\begin{array}{l}\text { The letter " } h \text { " is used to indicate hearable aspiration, its length proportional } \\
\text { to the number of h's. If preceded by a dot, the aspiration is an in-breath. } \\
\text { Aspiration internal to a word (e.g., laughter) is enclosed in parentheses. }\end{array}$ \\
\hline${ }^{\circ}$ word ${ }^{\circ}$ & $\begin{array}{l}\text { Talk appearing within degree signs is lower in volume relative to surrounding } \\
\text { talk. }\end{array}$ \\
\hline$(($ words $))$ & Words in double parentheses indicate transcriptionist's comments. \\
\hline
\end{tabular}

\section{Role of funding}

The research leading to these results has received funding from the People Programme (Marie Curie Actions) of the European's Union Seventh Framework Programme (FP7/2007-2013) under REA grant agreement $n^{\circ} 626893$. The contents of this paper reflect only the views of the author and not the views of the European Commission. 


\section{Acknowledgments}

I would like to thank Alessandra Fasulo, Chiara Ganapini and two anonymous reviewers for their thorough comments on earlier versions of this paper.

\section{Conflict of interest}

The author declares that there are no conflicts of interest.

\section{References}

(1) Muntigl P, Zabala LH. Expandable responses: How clients get prompted to say more during psychotherapy. Res Lang Soc Interact 2008;41:187-226.

(2) Antaki C, O'Reilly M. Either/or questions in child psychiatric assessments: The effect of the seriousness and order of the alternatives. Discourse Stud 2014;16:327-345.

(3) Hutchby I. Resisting the incitement to talk in child counselling: aspects of the utterance 'I don't know'. Discourse Stud 2002;4:147-168.

(4) Schegloff EA. Discourse as an interactional achievement: some uses of 'uh huh' and other things that come between sentences. In: Tannen D, editor. Analyzing Discourse: Text and Talk. Washington, D.C.: Georgetown University Press; 1981. 71-93.

(5) Peräkylä A, Silverman D. Owning Experience: Describing the Experience of Other Persons. Text 1991;11:441-480.

(6) Halonen M. Life stories used as evidence for the diagnosis of addiction in group therapy. Discourse \& Society 2006;17:283-298.

(7) Bercelli F, Rossano F, Viaro M. Supra-session courses of action in psychotherapy. J Pragmat 2013;57:118-137.

(8) Smith MS. "I thought" initiated turns: Addressing discrepancies in first-hand and second-hand knowledge. J Pragmat 2013;57:318-330.

(9) Peräkylä A. AIDS counselling: Institutional interaction and clinical practice. Cambridge: Cambridge University Press; 1995.

(10) Bergmann JR. Veiled morality: notes on discretion in psychiatry. In: Drew P, Heritage J, editors. Talk at work: interaction in institutional settings. Cambridge: Cambridge University Press; 1992. 137-162. 
(11) Pino M. Epistemic struggles in addiction Therapeutic Community meetings. In: Zuczkowski A, Bongelli R, Riccioni I, Canestrari C, editors. Communicating Certainty and Uncertainty in Medical, Supportive and Scientific Contexts. Amsterdam / Philadelphia: John Benjamins; 2014. 201-221.

(12) Campling P. Therapeutic communities. Adv Psychiatr Treat 2001;7:365-372.

(13) Haigh R. The quintessence of a therapeutic environment. In: Campling P, Haigh R, editors. Therapeutic Communities, past, present and future. London: Jessica Kingsley; 1999.

(14) Keenan S, Paget S. Service Standards for Therapeutic Communities (5th edition). London: Royal College of Psychiatrists' Research Unit; 2006.

(15) De Leon G, Wexler H. The Therapeutic Community for Addictions: An Evolving Knowledge Base. Journal of Drug Issues 2009;39:167-177.

(16) Shah D, Paget S. Service Standards for Addiction Therapeutic Communities (1st edition). London: The Royal College Psychiatrists'; 2006.

(17) Malivert M, Fatseas M, Denis C, Langlois E, Auriacombe M. Effectiveness of Therapeutic Communities: A Systematic Review. Eur Addict Res 2012;18:1-11.

(18) Mandell W, Edelen MO, Wenzel SL, Dahl J, Ebener P. Do dimensions of therapeutic community treatment predict retention and outcomes? Journal of Substance Abuse Treatment 2008; 35(3):223-231.

(19) Goethals I, Soyez V, Melnick G, Leon GD, Broekaert E. Essential Elements of Treatment: A Comparative Study Between European and American Therapeutic Communities for Addiction. Subst Use Misuse 2011;46:1023-1031.

(20) Goethals I, Vanderplasschen W, Vandevelde S, Broekaert E. Fixed and dynamic predictors of treatment process in therapeutic communities for substance abusers in Belgium. Subst Abuse Treat Prev Policy 2012;7:43.

(21) Huey Dye M, Ducharme LJ, Johnson JA, Knudsen HK, Roman PM. Modified Therapeutic Communities and Adherence to Traditional Elements. J Psychoactive Drugs 2009;41:275-283.

(22) Wootton AJ. Sharing : Some Notes on the Organization of Talk in a Therapeutic Community. Sociology 1977;11:333-350.

(23) Fasulo A. Theories of self in psychotherapeutic narratives. In: Bamberg M, De Fina A, Schiffrin D, editors. Selves and Identities in Narrative and Discourse. Amsterdam / Philadelphia: John Benjamins; 2007. 325-350.

(24) Steinberg DM. The Mutual-Aid Approach to Working with Groups: Helping People Help One Another. Binghamton, NY: The Haworth Press; 2004.

(25) Pomerantz A. Pursuing a response. In: Atkinson JM, Heritage J, editors. Structures of social action. Cambridge: Cambridge University Press; 1984. 152-163. 
(26) Pomerantz A. Telling My Side: "Limited Access" as a "Fishing" Device. Sociol Inq 1980; 34:186-198.

(27) Parry R, Land V, Seymour J. How to communicate with patients about future illness progression and end of life: a systematic review. BMJ Support Palliat Care 2014;4:331-341.

(28) Ten Have P. Doing Conversation Analysis (2nd ed.). London: Sage; 2007.

(29) Sidnell J. Conversation Analysis: An Introduction. Malden, MA: Wiley-Blackwell; 2010.

(30) Sidnell J, Stivers T. Handbook of Conversation Analysis. Boston: Wiley-Blackwell; 2013.

(31) Jefferson G. Glossary of transcript symbols with an introduction. In: Lerner GH, editor. Conversation Analysis: Studies from the first generation. Philadelphia: John Benjamins; 2004. 1323.

(32) Schegloff EA. Practices and Actions: Boundary Cases of Other-Initiated Repair. Discourse Process 1997;23:499-545.

(33) Raymond G. Grammar and social organization: Yes/no interrogatives and the structure of responding. Am Sociol Rev 2003;68:939-967.

(34) Button G, Casey N. Topic nomination and topic pursuit. Human Studies 1985; 8:3-55.

(35) Schegloff EA. Sequence organization in interaction: a primer in conversation analysis I. Cambridge: Cambridge University Press; 2007.

(36) Weiste E, Perakyla A. A Comparative Conversation Analytic Study of Formulations in Psychoanalysis and Cognitive Psychotherapy. Res Lang Soc Interact 2013;46:299-321.

(37) Muntigl P, Choi KT. Not remembering as a practical epistemic resource in couples therapy. Discourse Stud 2010; 12(3):331-356.

(38) Mortari L, Pino M. Conversational pursuit of medication compliance in a Therapeutic Community for persons diagnosed with mental disorders. Disabil Rehabil 2014;36:1419-1430.

(39) Heritage J. The Epistemic Engine: Sequence Organization and Territories of Knowledge. Res Lang Soc Interact 2012; 45(1):30-52.

(40) Heritage J. Territories of knowledge, territories of experience: empathic moments in interaction. In: Stivers T, Mondada L, Steensig J, editors. The Morality of Knowledge in Conversation. Cambridge: Cambridge University Press; 2011. 159-183.

(41) Muntigl P, Horvath AO. The therapeutic relationship in action: How therapists and clients comanage relational disaffiliation. Psychother Res 2014; 24(3):327-345.

(42) Pomerantz A. Giving a source of basis: the practice in conversation of telling 'how I know'. J Pragmat 1984; 607(625).

(43) Steensig J, Larsen T. Affiliative and disaffiliative uses of you say x questions. Discourse Stud 2008; 10(1):113-133. 
(44) Drew P. Contested evidence in courtroom cross-examination: the case of a trial for rape. In: Drew P, Heritage J, editors. Talk at work: interaction in institutional settings. Cambridge: Cambridge University Press; 1992. 470-520.

(45) Muntigl P, Horvath AO. "I Can See Some Sadness in Your Eyes": When Experiential Therapists Notice a Client's Affectual Display. Res Lang Soc Interact 2014; 47(2):89-108.

(46) O’Reilly M, Lester J, Muskett T. Children's claims to knowledge regarding their mental health experiences and professionals' negotiation of the problem. Patient Educ Couns. This issue.

(47) Pearce S, Pickard H. How therapeutic communities work: Specific factors related to positive outcome. Int J Soc Psychiatry 2013;59:636-45.

(48) Lerner GH. Finding "Face" in the Preference Structures of Talk-in-Interaction. Soc Psychol Q 1996;59:303-321.

(49) Fasulo A, Zinken J, Zinken K. 'What about' questions in chronic illness self-management meetings. Patient Educ Couns. This issue.

(50) Moore J. Knowledge as an Interactional Tool in the Management of Client Empowerment. Patient Educ Couns. This issue.

(51) Raymond G, Heritage J. The epistemics of social relations: Owning grandchildren. Lang Soc 2006;35:677-705.

(52) Heritage J, Raymond G. Navigating Epistemic Landscapes: Acquiescence, Agency and Resistance in Responses to Polar Questions. In: de Ruiter JP, editor. Questions: Formal, functional and interactional perspectives. Cambridge: Cambridge University Press; 2012. 179-192.

(53) Heritage J. Epistemics in Action: Action Formation and Territories of Knowledge. Res Lang Soc Interact 2012;45:1-29.

(54) Heritage J, Raymond G. The terms of agreement: Indexing epistemic authority and subordination in talk-in-interaction. Soc Psychol Q 2005;68:15-38.

(55) Heritage J. Action formation and its epistemic (and other) backgrounds. Discourse Stud 2013;15:551-578. 